\title{
IMPLANTAÇÃO DO SISTEMA DE PRODUÇÃO AGROECOLÓGICA INTEGRADA E SUSTENTT́́VEL EM COMUNIDADE DE VITÓRIA DE SANTO ANTÃO - PE
}

\section{IMPLEMENTATION OF THE SYSTEM INTEGRATED AND SUSTAINABLE AGROECOLOGICAL PRODUCTION IN VITÓRIA DE SANTO ANTÃO - PE}

\author{
Bruno Wallace do Carmo Perônico ${ }^{1}$; Maciel Alves Tavares²; José Miguel da Silva Neto³ \\ Lenira Batista da Silva ${ }^{4}$; Mércia Cardoso da Costa Guimarães ${ }^{5}$
}

DOI: https://doi.org/10.31692/978-65-991061-7-0.445-448

\section{INTRODUÇÃO}

A prática do trabalho em grupo (mutirão) tem como objetivo envolver estrategicamente o máximo de pessoas visando um melhor aproveitamento do tempo e do serviço, sendo esta prática muito utilizada na agricultura camponesa, com a finalidade de concluir trabalhos nas comunidades: plantio, construção de casas e barreiros.

O Sistema Produção Agroecológica Integrada e Sustentável (PAIS) é uma tecnologia social que visa à produção de alimentos em um sistema agroecológico, integrado e sustentável que tem como princípios fundamentais a integração da criação de animais com a produção vegetal, a preservação e respeito ao solo, ao meio ambiente e ao homem em condições trabalhistas, econômicas e sociais justas e ainda incentivar o associativismo entre os produtores apontando novos canais para boas colheitas agora e no futuro (FETAES, 2016).

Objetivou-se a realização de um mutirão, com alunos (do curso Técnico em Agropecuária e do superior em Agronomia) e professores do Instituto Federal de Pernambuco - IFPE campus Vitória, para realização da implantação de um Sistema PAIS na comunidade de Cacimbas, zona rural de Vitória de Santo Antão - PE.

\section{Relato de Experiência}

No dia 24/10/2018 foi realizado um Dia de Campo através de mutirão para implantação do sistema PAIS na comunidade de Cacimbas, parceira do IFPE em projetos institucionais de pesquisa e extensão.

A ação contou com a participação de estudantes do curso Técnico em Agropecuária e do Bacharelado em Agronomia e professores do IFPE. Chegamos à comunidade de Cacimbas

\footnotetext{
${ }^{1}$ Cursando Bacharelado em Agronomia, Instituto Federal de Pernambuco Campus Vitória de Santo Antão, brunowperonico1@gmail.com

${ }^{2}$ Cursando Bacharelado em Agronomia, Instituto Federal de Pernambuco Campus Vitória de Santo Antão, macieltavares15@gmail.com

${ }^{3}$ Cursando do Bacharelado em Agronomia, Instituto Federal de Pernambuco Campus Vitória de Santo Antão, josemiguelifpe@gmail.com

${ }^{4}$ Cursando Bacharelado em Agronomia, Instituto Federal de Pernambuco Campus Vitória de Santo Antão, lenirabso@hotmail.com

${ }^{5}$ Professora Doutora, Instituto Federal de Pernambuco Campus Vitória de Santo Antão, mercia.guimaraes@ vitoria.ifpe.edu.br
} 
pela manhã e nos reunimos na sede da associação, onde, nesse espaço tivemos contato com todos os participantes da atividade (Imagem 1), realizamos uma breve apresentação sobre o Sistema PAIS e descrevemos sobre a proposta da atividade a ser realizada (Imagem 2). Após todas as informações fomos a campo para conhecer o local e iniciar as atividades.

Imagem 1: Apresentação dos participantes na sede da associação. Fonte: Própria.

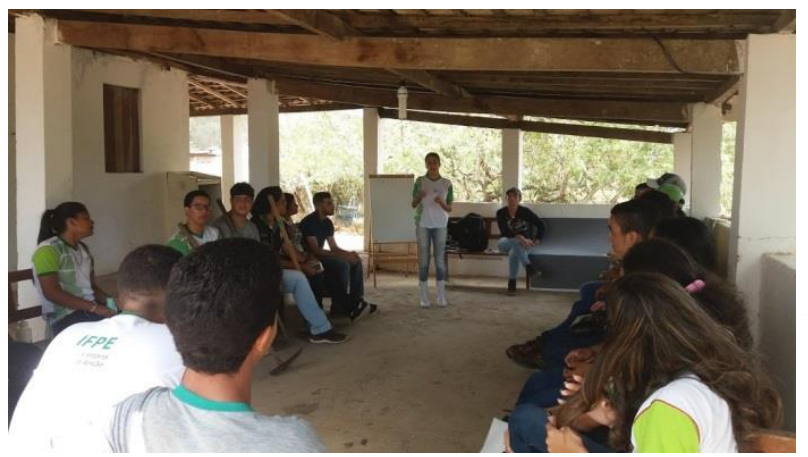

Imagem 2: Demonstração do PAIS em desenho. Fonte: Própria.

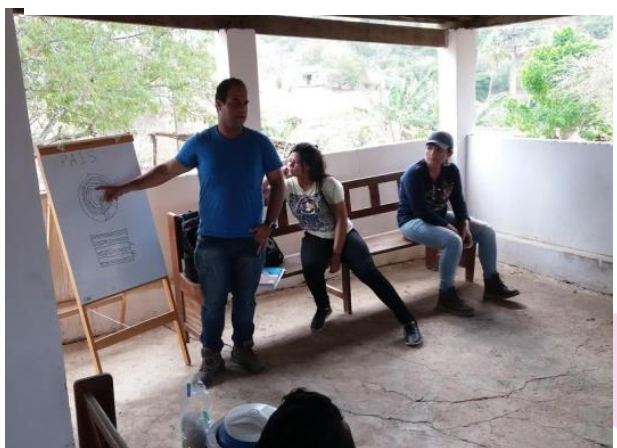

Ao chegarmos a área destinada a implantação do PAIS, definimos as atividades a serem realizadas e dividimos os participantes em quatro grupos: poda e construção do galinheiro (grupo 01), levantamento dos canteiros (grupo 02), tratamento dos páletes (grupo 03) e, fornecimento de material (grupo 04), sendo possível os grupos se revezarem ou membros trocarem de grupos, de acordo com a necessidade.

No centro da área utilizada existia um umbuzeiro, o qual foi podado para construirmos o galinheiro ao seu redor, e sucessivamente os canteiros no formato circular (Imagem 3 e 4). Para construção do galinheiro das aves utilizou-se páletes (estrados) de madeiras presos por estacas.

Imagem 3: O umbuzeiro na área sendo podado. Fonte: Própria.

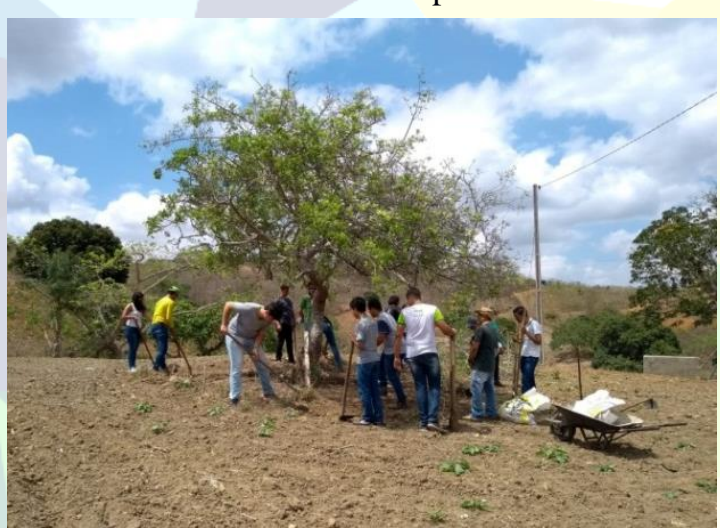

Imagem 4: Canteiros circulares ao redor do umbuzeiro. Fonte: Própria.

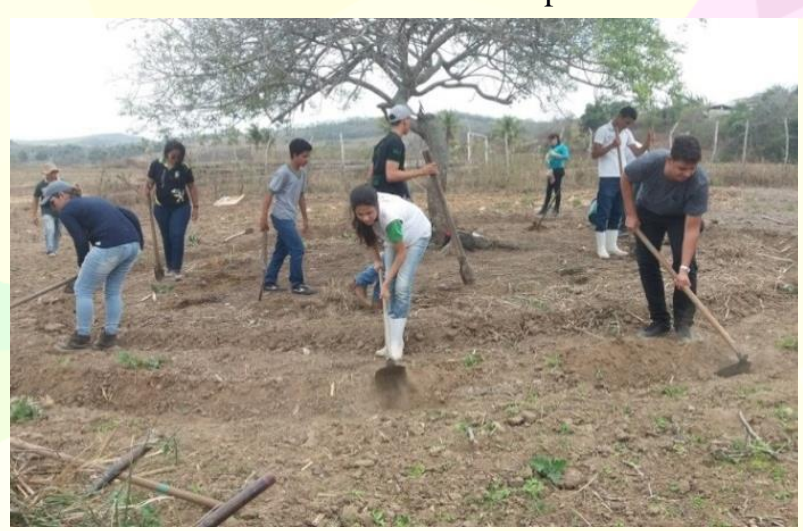

No período da manhã, conseguimos finalizar metade dos páletes com espaços 
definidos para que as aves não se dispersassem, covas cavadas para introduzir as estacas e canteiros descompactados e devidamente marcados. Almoçamos no IFPE e retornamos para a comunidade onde reiniciamos as atividades de campo. O grupo do pálete concluiu a atividade, o grupo do galinheiro iniciou a fixação das estacas e páletes, o grupo dos canteiros iniciou o levantamento dos canteiros (Imagem 5 e 6). No final da tarde encerramos as atividades e realizamos uma avaliação, em seguida retornamos ao IFPE.

Imagem 5: Fixação das estacas do galinheiro. Fonte: Própria.

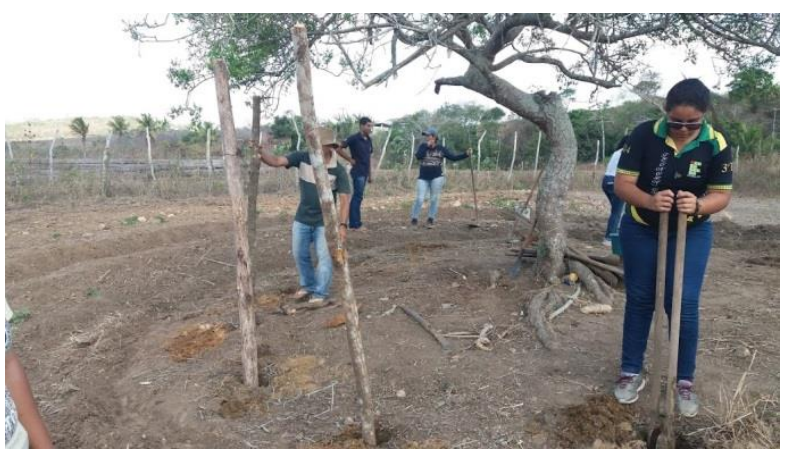

Imagem 6: Tratamento dos paletes para o galinheiro. Fonte: Própria.

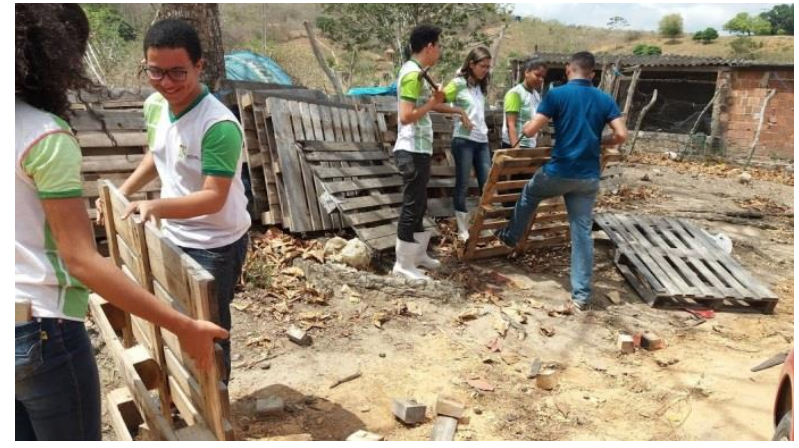

Durante a avaliação do Dia de Campo as considerações mais frequentes foram: quero voltar para concluir; foi muito bom, liguei teoria à prática; foi cansativo mais contribuiu com meu aprendizado; serviu para aplicar meus conhecimentos e; aprendi técnicas para aplicar em meu sítio. Pedimos também para recomendar melhorias e as mais faladas foram: conseguir mais material; utilização de garrafas PETs de alguma forma na estrutura e, na próxima vez procurar mais pessoas. Conseguiu-se concluir os canteiros e a primeira etapa do galinheiro, faltando apenas uma camada de páletes e a cobertura (Imagem 7 e 8).

Imagem 7: Resultado do trabalho. Fonte: Própria.

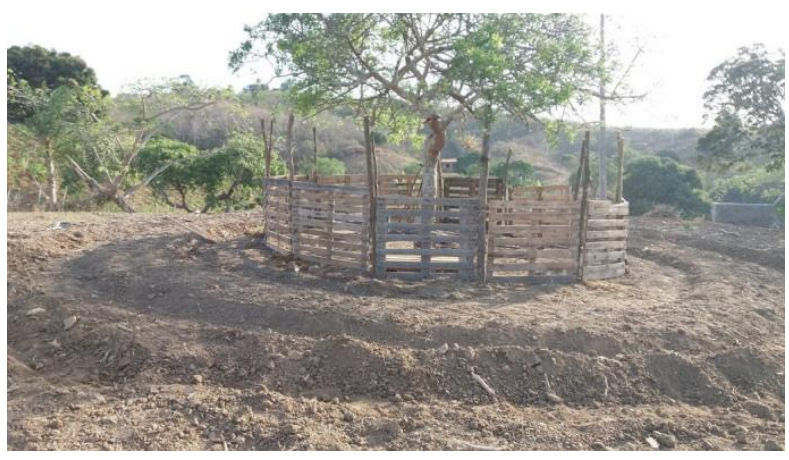

Imagem 8: Imagem com do grupo que participou da atividade. Fonte: Própria.

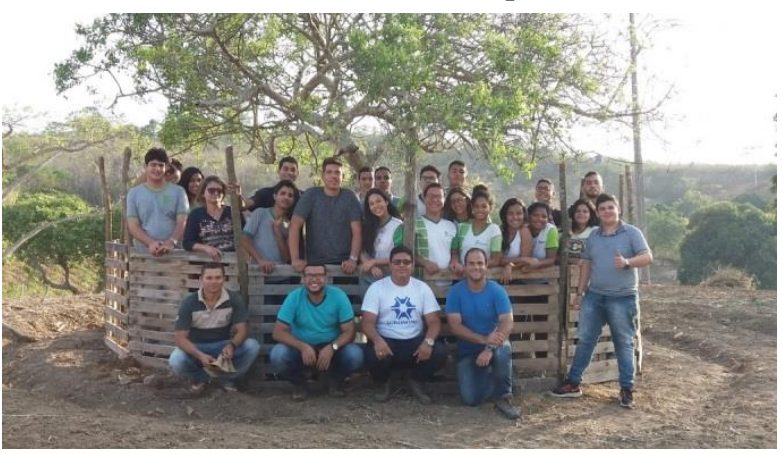

\section{CONSIDERAÇÕES}

A atividade de campo conseguiu motivar os participantes, que demonstraram 
interesse em participar de novos mutirões nesta e posteriormente em outras comunidades, pois a implantação do sistema PAIS irá contribuir e melhorar a qualidade de vida dos agricultores e criadores de Cacimbas.

Durante o processo os alunos e professores foram bem participativos e demonstraram entusiasmo durante as atividades, relacionando a teoria com a prática.

\section{REFERÊNCIAS}

FETAES. PAIS - Produção Agroecológica Integrada e Sustentável. Disponível em: <http://www.fetaes.org.br/main.asp?link=indep\&id=37>. Acesso em: 01 nov. 2018. 